\title{
Divulgar investigación en nutrición, uno de los propósitos del Premio José Félix Patiño Restrepo
}

\section{Communication on nutrition research, one of the purposes of the José Félix Patiño Restrepo Award}

Fanny Aldana-Parra ${ }^{1 *}$

https://doi.org/10.35454/rncm.v2n1.064

La transformación o integración de Colciencias en el nuevo Ministerio de Ciencia, Tecnología e Innovación en Colombia, que tendrá, entre otras funciones, fortalecer una cultura basada en la generación, apropiación y divulgación del conocimiento y la investigación científica, nos obliga a reflexionar sobre nuestra participación en la generación del nuevo conocimiento, desde la experticia de cada profesional, y desde su ámbito de práctica nutricional. Esto implica, desde la nutrición, generar propuestas concretas de investigación a partir de contextos de práctica profesional específicos.

Sin embargo, en alimentación y nutrición los problemas son complejos. El carácter multifactorial de las enfermedades relacionadas con la dieta, determinan un nivel de complejidad mayor al intentar resolverlas. A pesar de esto, los avances son indiscutibles. La investigación científica ha mostrado, por ejemplo, que una disminución de 10 - $15 \mathrm{~kg}$ en un año con cambios consistentes en el estilo de vida puede reducir el riesgo de DM2 en $57 \%^{(1)}$. Igualmente, han mostrado el impacto de la dieta en la composición de la microbiota intestinal y su asociación con el riesgo de cáncer de colon ${ }^{(2)}$. Pero también, las caracterizaciones en poblaciones en riesgo han mostrado la importancia, entre otras, de evitar la malnutrición hospitalaria ${ }^{(3)}$. En cuanto al impacto económico, en Estados Unidos se estima que por cada dólar invertido en investigación por el Instituto Nacional de Salud (NIH), se generan US\$2,2 en crecimiento económico. Por otra parte, en 2018, Colciencias tuvo un presupuesto de inversión de $\$ 314,078$ millones de pesos destinados al fomento del conocimiento ${ }^{(4)}$.

Aunque el recurso económico en investigación es uno de los pilares de su desarrollo, pero a su vez escaso en nuestro país, también es cierto que el nutricionista dietista tiene a su disposición datos de valoraciones nutricionales y de ingesta invaluables, con los cuales bien se podrían realizar caracterizaciones del estado nutricional, que contribuyan a definir factores de riesgo y tipificaciones de la población que intervienen en sus instituciones. Esta es la esencia del NutritionDay, en el caso de la malnutrición hospitalaria.

Poner a disposición de la sociedad el conocimiento que se genera como consecuencia de las actividades en investigación, es nuestro deber y responsabilidad. La propuesta de la Declaración de Cartagena 2019, promovida por la ACNC y la FELANPE, menciona

1 Investigadora Pontificia Universidad Javeriana, Departamento de Nutrición y Bioquímica, Bogotá, D.C., Colombia

Coordinadora del Premio José Félix Patiño Restrepo, ACNC.

*fannyaldanaparra@yahoo.com 
como cuarto objetivo "Impulsar el desarrollo de la investigación y la educación en nutrición clínica”, bajo el paradigma de abordar el problema nutricional desde un mejor conocimiento del estado metabólico y nutricional del paciente.

El interés tanto del gobierno en la creación de un nuevo Ministerio de Ciencia, Tecnología e Innovación, así como de las asociaciones por promover la investi- gación en nutrición, se ve complementado por iniciativas como el Premio de Investigación José Félix Patiño Restrepo. Participar en la convocatoria del premio va más allá de un reconocimiento económico. Es la oportunidad retribuir a la sociedad nuestros hallazgos en nutrición y de divulgar no solo el conocimiento sino también el esfuerzo que implica realizar investigación en países en vía de desarrollo como el nuestro.

\section{CIFRAS DE LA CONVOCATORIA 2019 DEL PREMIO JOSÉ FÉLIX PATIÑO RESTREPO}

Total de trabajos inscritos: 67.

- 20 protocolos de investigación.

- 14 trabajos de grado.

- 33 trabajos libres.

- 10 trabajos internacionales de México, Paraguay, Ecuador, Perú y Costa Rica.

Puede consultar los resúmenes de todos los trabajos y protocolos en la página web de la revista: https://revistanutricionclinicametabolismo.org/la-revista/

\section{Referencias bibliográficas}

1. Lean ME, Leslie WS, Barnes AC, Brosnahan N, Thom G, McCombie L, et al. Primary care-led weight management for remission of type 2 diabetes (DiRECT): an open-label, cluster-randomised trial. Lancet. 2018;391(10120):541-51.

2. Tilg H, Adolph TE, Gerner RR, Moschen AR. The intestinal microbiota in colorectal cancer. Cancer cell. 2018;33(6):954-64.
3. Agarwal E, Ferguson M, Banks M, Vivanti A, Batterham M, Bauer J, et al. Malnutrition, poor food intake, and adverse healthcare outcomes in non-critically ill obese acute care hospital patients. Clin Nut. 2018; doi: 10.1016/j.clnu.2018.02.033.

4. Research America. Reseach: an economic driver. Arlington, VA, USA. Citado 18 marzo 2019. Recuperado de: https:// www.researchamerica.org/sites/default/files/Economic\%20 driver_2017.pdf 